\title{
A ANÁLISE DO COMPORTAMENTO NECESSITA UM CHOQUE DE BEHAVIORISMO
}

\section{BEHAVIOR ANALYSIS NEEDS A SHOCK OF BEHAVIORISM}

\author{
LINCOLN DA SILVA GIMENES
}

UNIVERSIDADE DE BRASÍLIA, BRASIL

\section{RESUMO}

O texto é uma reflexão sobre o distanciamento entre as áreas básica e aplicada para aqueles que ensinam e atuam como analistas do comportamento. Entre os fatores que contribuem para o distanciamento encontram-se o afastamento do laboratório e o decorrente prejuízo para a formação de pesquisadores e profissionais em suas análises funcionais; a disputa falaciosa entre análises molares e moleculares, que leva à rejeição de terminologia básica da análise do comportamento; a alta demanda por atendimento em autismo e TDAH e o consequente aumento na oferta de emprego; o diagnóstico cada vez mais estendido, pressionado pelas indústrias farmacêuticas. A demanda por terapia de resultados pode levar à miscelânea terapêutica, que descaracteriza a análise comportamental aplicada. Profissionais que se intitulam analistas do comportamento abandonaram a análise funcional ou a fazem de forma superficial ou incompleta. Discussões separatistas que refletem disputa de poder deveriam ser substituídas por estratégias de integração entre as áreas básica e aplicada e melhoria da formação para manter o rigor da análise do comportamento e a fidelidade ao behaviorismo.

Palavras-chave: análise do comportamento, distanciamento pesquisa básica x aplicada, formação em análise do comportamento.

ABSTRACT

The text is a reflection on the gap between the basic and applied areas for those who teach and practice as behavior analysts. Among factors that contribute to this gap are the reduction of activities in the laboratory, impoverishing the training of researchers and professionals in their functional analyzes; the fallacious dispute between molar and molecular analyzes that is leading to the rejection of basic terminology of behavior analysis; the high demand for treatment of autism and ADHD and the consequent increase in the offer of employment; and the diagnosis increasingly extended, pressured by the pharmaceutical industry. The demand for therapy of results can lead to therapeutic miscellaneous, which does not characterize the applied behavioral analysis. Many professionals who call themselves behavior analysts have abandoned functional analysis or do so superficially or incompletely. Separatist discussions that reflect struggles for power should be replaced by integration strategies between the basic and applied areas and improvement of training to maintain rigorous behavioral analysis and fidelity to behaviorism.

Key words: behavioral analysis, basic research, applied research, training in behavioral analysis

\footnotetext{
Este texto foi elaborado por Lincoln Gimenes, em fase avançada da doença do neurônio motor. Desprovido do controle de movimentos, Lincoln ditou para Elenice Hanna as suas formulações utilizando apenas o movimento dos olhos. Um cartaz com as letras do alfabeto era posicionado na frente de seus olhos e as letras de cada linha eram percorridas com o dedo indicador, parando em uma letra quando ele piscava. Quando uma palavra parecia ter sido formada, ela era dita em voz alta e ele confirmava ou repetia o ditado. O texto era construído lentamente, com pausas de alguns dias entre os encontros. Cada sessão iniciava com a leitura do trecho anterior para verificar se algo precisava ser modificado. Lincoln parecia ter o texto totalmente pronto "na cabeça" e nunca parava para pensar sobre a próxima palavra. O texto foi apresentado como palestra no XXIV Encontro da Associação Brasileira de Psicologia e Medicina Comportamental em 2015, São Paulo.
} 
Os mais velhos perceberão que o título foi inspirado no discurso do senador Mario Covas no final dos anos 80, intitulado "O Brasil necessita um choque de capitalismo". O discurso teve grande impacto no Congresso e no Palácio do Planalto e o levou à candidatura à presidência da república. Ele não venceu, mas o impacto podia ainda ser sentido doze anos depois, no primeiro mandato do presidente Lula.

Não pretendo que meu discurso tenha a mesma repercussão que o de Covas, mas que sirva de ponto para reflexão para aqueles que ensinam e atuam como analistas do comportamento.

Nos anos 80, em seu discurso presidencial na ABAI, então ABA, Donald Baer apresentou o texto " $A$ flight from the laboratory", "Um voo para fora do laboratório", incentivando trabalhos na área aplicada. No ano seguinte, Skinner apresentou o trabalho "A flight back to the laboratory", "Um vôo de volta para o laboratório", alertando para esse pulo sem uma base ainda bem consolidada. $\mathrm{O}$ que faltava era uma ponte de transição que deveria se tornar uma permanente ponte de mão dupla, com o laboratório alimentando a aplicação e a área aplicada alimentando o laboratório para realizar pesquisa mais representativa do mundo real.

O alerta de Skinner é válido até hoje, pois ainda vemos analistas que abandonaram a análise funcional como se fosse coisa de laboratório, ou a fazem de forma superficial ou incompleta. Isso contribui cada vez mais para o distanciamento entre as áreas básica e aplicada.

Uma discussão iniciada entre Davison e Baum tem contribuído para o distanciamento entre as áreas aplicada e básica, cada um defendendo análise molecular e molar, respectivamente, como antagônicas quando, na verdade, elas são complementares. Só assim os fenômenos comportamentais podem ser completamente compreendidos. Essa discussão tem levado, inclusive, à rejeição de terminologia básica, como contingência e reforçamento. Precisamos tomar cuidado para não perder as árvores pela floresta. No reflorestamento, cada árvore é plantada individualmente e de forma planejada. Podemos reconhecer uma floresta, mas só a conhecemos se conhecermos cada uma de suas árvores. Robin Hood tinha sucesso nas suas intervenções porque conhecia muito bem a floresta de Sherwood.

A alta demanda por atendimento nas áreas de autismo e TDAH e o consequente aumento na oferta de emprego também deve ser considerado no distanciamento da área aplicada dos fundamentos da análise do comportamento. $\mathrm{O}$ diagnóstico tem sido um vilão nessa história. Há algumas décadas, quando fiz meu curso de graduação, uma criança autista era definida como aquela ensimesmada, não respondendo a estímulos externos, com gestos repetitivos, algumas vezes autolesivos. Apesar de uma definição topográfica, era fácil identificar essas crianças, incluindo adolescentes e adultos. Hoje o diagnóstico foi tão estendido que qualquer um de nós, em algum momento foi, é, ou será autista. Quanto maior o número de pessoas diagnosticadas, maior o lucro das indústrias farmacêuticas, que de alguma forma contribuem para essa elasticidade diagnóstica. Apesar da análise do comportamento ter sido indicada como a principal forma de intervenção nesses casos, a demanda por terapia de resultados pode levar à miscelânea terapêutica, que descaracteriza qualquer vestígio da análise do comportamento.

Com o TDAH tem acontecido coisa semelhante. Quem de nós nunca sonhou acordado em sala de aula ou ficou inquieto na carteira se esfregando e até quebrando o lápis por medo de pedir à professora para ir ao banheiro? Uma professora mal treinada identifica esses comportamentos como sendo TDAH e encaminha a criança para o serviço médico, que geralmente confirma o diagnóstico e prescreve alguns medicamentos. Estamos adoecendo nossas crianças, que muitas vezes tomam drogas pesadas sem necessidade. A falta de uma análise funcional contribui para esse estado de coisas. A indústria farmacêutica também influencia o diagnóstico por meio de seus incentivos para a prescrição de certos medicamentos. Esses incentivos incluem refeições em restaurantes caros, férias na praia e participações em congressos em locais paradisíacos. A teoria de detecção de sinais explica muito bem essa decisão diagnóstica. De alguma forma, estamos nos submetendo a diagnósticos impostos por interesses outros que não a saúde das crianças e adolescentes.

As recentes discussões separatistas também não contribuem para a integração das áreas. Essas discussões têm sido mais políticas do que epistemológicas. $\mathrm{Na}$ verdade, é mais uma luta por poder. Poder esse que, do meu ponto de vista, apesar de servir para promoção pessoal, é efêmero.

Se há alguma coisa errada com a área aplicada, devemos nos juntar e tentar consertar, ao invés de adotar uma estratégia que, do meu ponto de vista, parece ser suicida. Numa época em que estamos procurando integração, inclusive com outras áreas do conhecimento, não devemos ir na contramão. Meu orientador Izzi Goldiamond costumava dizer que um bom experimentalista poderia ser um bom clínico, mas um bom clínico dificilmente seria um bom experimentalista. $\mathrm{O}$ que deveríamos fazer é treinar nossos clínicos como ser bons experimentalistas para que mantivessem o rigor da análise do comportamento e a fidelidade ao behaviorismo.

$\mathrm{Eu}$ sei que com esse discurso "eu posso não lhe agradar..., mas [venho] para [tentar] consertar" (Vandré, 1966).

\section{REFERÊNCIAS}

Baer, D. M. (1978). On the relation between basic and applied research. In A. C. Catania \& T. A. Brigham (Eds.). Handbook of applied behavior analysis: Social and instructional processes. New York: Irvington.

Cullen, C. (1981). The flight to the laboratory. The Behavior Analyst, 4, 81-83.

Pierce, W. D., \& Epling, F. W. (1980). What happened to analysis in applied behavior analysis? The Behavior Analyst, 3, 1-9.

Vandré, G. (1966). Disparada. Acesso em www.vagalume.com.br/geraldo-vandre/disparada.html

Artigo convidado. Recebido em 23/09/2016. 